\title{
Serum lipids and their associations with viral levels and liver disease severity in a treatment-naïve chronic hepatitis $C$ type 1-infected cohort
}

\author{
D. Ramcharran, ${ }^{1}$ A. S. Wahed, ${ }^{2}$ H. S. Conjeevaram, ${ }^{3}$ R. W. Evans, ${ }^{1}$ T. Wang, ${ }^{4}$ S. H. Belle ${ }^{1,2}$ \\ and L. J. Yee ${ }^{1,5}{ }^{1}$ Department of Epidemiology, Graduate School of Public Health, University of Pittsburgh, Pittsburgh, PA, USA; ${ }^{2}$ Department of \\ Biostatistics, Graduate School of Public Health, University of Pittsburgh, Pittsburgh, PA, USA; ${ }^{3}$ Division of Gastroenterology, School of Medicine, \\ University of Michigan, Ann Arbor, MI, USA; ${ }^{4}$ Department of Infectious Disease and Microbiology, Graduate School of Public Health, University of \\ Pittsburgh, Pittsburgh, PA, USA; and ${ }^{5}$ Division of Infectious Diseases, School of Medicine, University of Pittsburgh, Pittsburgh, PA, USA
}

Received March 2010; accepted for publication September 2010

\begin{abstract}
SUMMARY. In patients with chronic hepatitis C virus (HCV) infection, steatosis and fibrosis have been shown to be inversely associated with total cholesterol (TC) and lowdensity lipoprotein cholesterol. Steatosis and fibrosis have also been found to be associated with triglyceride (TG) levels; though, the direction of the relationship is inconsistent across studies. The objective of this study was to assess whether viral level and histological factors are associated with the serum lipid profile in a treatment-naïve cohort with chronic HCV genotype 1 infection. Participants were from the prospective Study of Viral Resistance to Antiviral Therapy (Virahep-C). Fasting lipid profiles were analysed for 160 African Americans and 170 Caucasian Americans. Linear regression was used to evaluate associations of each lipid with viral load and liver disease. TG levels were significantly and directly associated with $\mathrm{HCV}$ levels $(P=0.0034)$ and
\end{abstract}

steatosis $(P<0.0001)$. Other lipid parameters were significantly lower in those with fibrosis [HDLc $(P=0.001)$ and TC levels $(P=0.004)]$ than in those without fibrosis. In patients with $\mathrm{HCV}$ genotype 1 infection, more severe liver disease was associated with lower lipid levels, with the exception of TG levels that were directly related to steatosis. The direct relationship between viral load and TG levels is consistent with proposed the mechanisms of very low density lipoprotein/HCV particle secretion. In contrast, the direct relationship between TG level and steatosis is inconsistent with posited mechanisms of $\mathrm{HCV}$-induced steatosis, a possible reflection of $\mathrm{HCV}$ genotype 1 infection and a metabolic aetiology of steatosis.

Keywords: cholesterol, fibrosis, hepatitis C, hepatitis C virus, lipoprotein, steatosis, serum lipids.
In the United States, approximately 3.2 million noninstitutionalized people have chronic hepatitis $\mathrm{C}$ virus (HCV) infection [1,2]. The estimated direct US health care cost of HCV in 1997, including liver transplantation for which chronic HCV ranks as the leading indication, was $\$ 1.8$ billion $[3,4]$. These statistics underscore the significant public health burden of chronic HCV infection.

Abbreviations: AA, African American; ALT, alanine aminotransferase; AST, aspartate aminotransferase; ATP, Adult Treatment Panel; BMI, body mass index; CA, Caucasian American; HAI, histological activity index; HCV, hepatitis C virus; HDLc, high-density lipoprotein cholesterol; INR, international normalized ratio; LDLc, low-density lipoprotein cholesterol; SR-B1, scavenger receptor-B1; $\mathrm{TC}$, total cholesterol; TG, triglyceride; TIBC, total iron binding capacity; Virahep-C, Viral Resistance to Antiviral Therapy; VLDL, very low density lipoprotein; WBC, white blood cell count.

Correspondence: Darmendra Ramcharran, PhD, MPH, 24 Doylston Drive, Cranston, RI 02905, USA. E-mail: dramcharran@gmail.com
Recent reports suggest that serum lipids may be relevant to $\mathrm{HCV}$ and its life cycle. Compared to people without $\mathrm{HCV}$ infection, people with chronic HCV tend to have lower total cholesterol (TC), low-density lipoprotein cholesterol (LDLc) and high-density lipoprotein cholesterol (HDLc) levels [5-8]. Triglycerides (TG) have also been associated with HCV infection with reports of both lower [5-8] and higher levels [9], the opposite direction of the relationships possibly reflecting the impact of different host factors.

In both noninfected and HCV-infected cohorts, lipids have been associated with liver disease measures, including steatosis, fibrosis and cirrhosis [10-14]. In a non-HCV exposed cohort, TG and HDLc were directly and inversely related to steatosis, respectively, and no significant association was found with LDLc [11]. Among chronic HCV-infected cohorts, inverse relationships of TC and LDLc with steatosis and fibrosis have been reported [12,13]. TGs have also been 
associated with steatosis, although inversely in a study of genotype 3 infection [13] and directly in another report of genotype 1 infection [10]. Furthermore, compared to control patients, liver cirrhosis has been associated with lower LDLc, HDLc and TC levels, with lower TC levels limited to patients with chronic active hepatitis [14].

Findings from in vitro work support a mechanism involving $\mathrm{HCV} /$ lipoprotein complexes and LDL receptor or scavenger receptor-B1 (SR-B1)-meditated HCV entry into hepatocytes [15-18]. However, the LDL receptor-mediated mechanism is controversial $[19,20]$. Entry of free HCV (not bound with lipoproteins) may also occur through SR-B1 or CD81 [20-22]. Other work posits a process of HCV viral particle assembly and secretion related to very low density lipoprotein (VLDL) metabolic pathways [23-27]. In addition, the interaction of the HCV core with microsomal TG transfer protein has been shown to disrupt VLDL secretion resulting in intrahepatic TG accumulation, a possible mechanism of HCV-induced steatosis [26].

The relationships among serum lipids, liver disease, and possible HCV entry, replication and secretion processes are complex. This study characterizes factors associated with serum lipids in a treatment-naïve cohort with chronic HCV genotype 1 infection. This report is relevant to in vitro and animal model studies that propose potential pathogenic mechanisms of HCV-induced liver damage, as well as mechanisms of HCV entry into hepatocytes from the serum, replication and secretion.

\section{METHODS}

\section{Study population}

Participants were drawn from The Study of Viral Resistance to Antiviral Therapy of Chronic Hepatitis C (Virahep-C) cohort, which has been previously described [28]. In brief, the Virahep-C study included 196 African American (AA) and 205 Caucasian American (CA) treatment-naïve patients with HCV genotype 1 infection to investigate the clinical, immunological, virological and host genetic factors that contribute to the racial disparity in antiviral treatment efficacy. Participants between the ages of 18 and 70 years with chronic HCV infection were treated with pegylated interferon alfa-2a and ribavirin combination therapy for up to 48 weeks. Lipid profile analyses were conducted among participants who consented to participate in host genetic studies $(n=374)$ and had available stored fasting serum samples at baseline $(n=335)$. Five participants who reported use of lipid-lowering agents at the screening evaluation were excluded from the statistical analysis. The final sample included in this analysis consisted of 330 participants (160 AA and $170 \mathrm{CA})$. This study was approved by the University of Pittsburgh's Institutional Review Board, and informed consent was received from the human subjects or their representatives. The study protocol conforms to the ethical guidelines of the 1975 Declaration of Helsinki as reflected in a priori approval by the institutions human research committee.

\section{Study measures}

Estimates of the lipid fractions, TG, LDLc, HDLc and TC, were obtained through analysis of stored fasting serum samples at the Heinz Nutrition Laboratory in the Department of Epidemiology at the University of Pittsburgh using spectrophotometric methods. If TG levels were $<400 \mathrm{mg} / \mathrm{dL}$, the Friedewald formula was used to calculate LDLc indirectly $($ LDLc $=\mathrm{TC}-\mathrm{HDLc}-0.20 \times \mathrm{TG})[29]$. Samples for which TG levels were at least $400 \mathrm{mg} / \mathrm{dL}(n=3)$ had LDLc assessed directly. Dyslipidaemia was defined using the cut-offs from the National Cholesterol Education Program (NCEP) Adult Treatment Panel III recommendations as any of the following: $\mathrm{LDLc} \geq 130 \mathrm{mg} / \mathrm{dL}, \mathrm{HDLc}<40 \mathrm{mg} / \mathrm{dL}, \mathrm{TC} \geq 200 \mathrm{mg} /$ dL or TG $\geq 150 \mathrm{mg} / \mathrm{dL}$ [30].

Biopsy-assessed liver disease measures included inflammation, fibrosis score, fat score and iron score. Inflammation and fibrosis were assessed using the criteria of the histological activity index (HAI) (range 0-12 and 0-6, respectively) by a single hepatopathologist [31,32]. An Ishak fibrosis score of at least three was classified as severe fibrosis, and steatosis was defined as a fat score of greater than zero (range 0-4) representing at least 5\% fat involvement of hepatic tissue. An iron score of 0,1 or 2 was assigned according to the amount of iron deposits in hepatic tissue. Summing non-Ishak fibrosis scores from the HAI, a total HAI inflammation score was calculated. HAI inflammation scores between 0-6 were classified as mild, 7-11 as moderate and 12 or greater as severe. Total HAI inflammation, Ishak fibrosis and fat scores were also analysed. Other nonbiopsy serological liver disease indicators included alanine and aspartate aminotransferase (ALT and AST, respectively), alkaline phosphatase, total bilirubin, the international normalized ratio (INR), white blood cell count (WBC), platelet count, serum ferritin and the per cent iron saturation [iron/ total iron-binding capacity (TIBC)].

\section{Statistical analysis}

Categorical measures were summarized as frequency and per cent with differences across groups on nominal scales (race, gender, health insurance status, employment status, smoking status, alcohol consumption of at least two drinks per week, history of diabetes and hypertension, HCV genotype and severe fibrosis) assessed using a Pearson's chi-squared test or the exact equivalent. Differences in categorical measures across ordered groups (education, HAI scores and iron scores) were assessed using a Jonckheere-Terpstra test or the exact equivalent. Continuous measures were summarized as medians and interquartile ranges with differences in group distributions assessed using the Wilcoxon rank sum or a 
Table 1 Cohort characteristics

\begin{tabular}{|c|c|c|c|c|}
\hline Feature* $^{*}$ & Overall $(n=330)$ & AA $(n=160)$ & $\mathrm{CA}(n=170)$ & $P \dagger$ \\
\hline \multicolumn{5}{|l|}{ Demographics } \\
\hline Age (years) & $48(43,52)$ & $48(45,52)$ & $47(42,52)$ & 0.07 \\
\hline Male & $216(65.5)$ & $106(66.3)$ & $110(64.7)$ & 0.77 \\
\hline \multicolumn{4}{|l|}{ Health insurance $(m=6) \ddagger$} & 0.008 \\
\hline Uninsured & $58(17.9)$ & $21(13.4)$ & $37(22.2)$ & 0.04 \\
\hline Public & $79(24.4)$ & $49(31.2)$ & $30(18.0)$ & 0.006 \\
\hline Private & $187(57.7)$ & $87(55.4)$ & $100(59.9)$ & 0.42 \\
\hline \multicolumn{4}{|l|}{ Education $(m=8) \S$} & 0.008 \\
\hline Less than high school & $61(18.9)$ & $36(23.1)$ & $25(15.1)$ & 0.07 \\
\hline High school degree & $78(24.2)$ & $41(26.3)$ & $37(22.3)$ & 0.16 \\
\hline Some college & $105(32.6)$ & $50(32.1)$ & $55(33.1)$ & 0.16 \\
\hline College degree or more & $78(24.2)$ & $29(18.6)$ & $49(29.5)$ & - \\
\hline Employed $(m=4)$ & $204(62.6)$ & $101(63.9)$ & $103(61.3)$ & 0.63 \\
\hline \multicolumn{5}{|l|}{ Health risk behaviours } \\
\hline Current smoker $(m=6)$ & $128(39.5)$ & $65(41.7)$ & $63(37.5)$ & 0.44 \\
\hline $\begin{array}{c}\text { Consumes } \geq 2 \text { alcoholic } \\
\text { drinks/week }(m=7)\end{array}$ & $66(20.4)$ & $38(24.2)$ & $28(16.9)$ & 0.10 \\
\hline \multicolumn{5}{|l|}{ General clinical features } \\
\hline $\mathrm{BMI}(m=5)$ & $28.4(25.2,32.4)$ & $29.3(26.6,33.9)$ & $27.4(24.4,31.4)$ & $<0.001$ \\
\hline Waist-to-hip ratio $(m=23)$ & $0.9(0.9,1.0)$ & $0.9(0.8,1.0)$ & $0.9(0.8,1.0)$ & 0.44 \\
\hline Diabetic & $31(9.4)$ & $24(15.0)$ & $7(4.1)$ & $<0.001$ \\
\hline Hypertensive & $97(29.4)$ & $64(40.0)$ & $33(19.4)$ & $<0.001$ \\
\hline \multicolumn{5}{|l|}{ Viral characteristics } \\
\hline $\log _{10}$ HCV level $(m=1)$ & $6.5(5.6,6.7)$ & $6.4(5.6,6.7)$ & $6.5(5.6,6.8)$ & 0.25 \\
\hline \multicolumn{4}{|l|}{ HCV genotype } & 0.002 \\
\hline 1, NOS & $25(7.6)$ & $10(6.3)$ & $15(8.8)$ & 0.38 \\
\hline $1 \mathrm{a}$ & $177(53.6)$ & $79(49.4)$ & $98(57.7)$ & 0.13 \\
\hline $1 \mathrm{a} / \mathrm{b}$ & $11(3.3)$ & $1(0.6)$ & $10(5.9)$ & 0.01 \\
\hline $1 b$ & $117(35.5)$ & $70(43.8)$ & $47(27.7)$ & 0.002 \\
\hline \multicolumn{5}{|l|}{ Liver disease indicators } \\
\hline ALT (U/L) & $69(45,108)$ & $60(40,88)$ & $74.5(52,139)$ & $<0.001$ \\
\hline AST (U/L) & $52(37,79)$ & $51.5(35.5,71.5)$ & $53(38,87)$ & 0.08 \\
\hline Alk phosphatase (U/L) & $79(62,103)$ & $83(62,108)$ & $78(63,96)$ & 0.043 \\
\hline Total bilirubin (mg/dL) & $0.6(0.5,0.8)$ & $0.6(0.4,0.8)$ & $0.7(0.5,0.9)$ & 0.004 \\
\hline INR $(m=2)$ & $1.0(0.9,1.1)$ & $1.0(0.9,1.1)$ & $1.0(0.9,1.1)$ & 0.95 \\
\hline WBC count $\left(10^{3} / \mathrm{mL}\right)(\mathrm{m}=3)$ & $6.0(4.7,7.3)$ & $5.7(4.6,7.3)$ & $6.25(4.9,7.4)$ & 0.055 \\
\hline Platelet count $\left(10^{3} / \mathrm{mL}\right)(m=4)$ & $207.5(161,257)$ & $212(159,268)$ & $207(161,242)$ & 0.33 \\
\hline Ferritin $(\mathrm{ng} / \mathrm{mL})(m=2)$ & $204(96.8,366)$ & $246(122,422)$ & $149(78,287)$ & $<0.001$ \\
\hline Albumin $(\mathrm{g} / \mathrm{dL})(m=2)$ & $4.2(4.0,4.4)$ & $4.2(3.9,4.4)$ & $4.2(4.0,4.5)$ & 0.004 \\
\hline Iron/TIBC $(m=8)$ & $34.1(26.2,44.0)$ & $33.9(25.7,41.9)$ & $34.3(26.4,47.7)$ & 0.18 \\
\hline Ishak fibrosis score $(m=1)$ & $2(1,3)$ & $2(1,3)$ & $2(1,3)$ & 0.85 \\
\hline Ishak fibrosis score $\geq 3(m=1)$ & $123(37.4)$ & $58(36.5)$ & $65(38.2)$ & 0.74 \\
\hline Fat score $(m=1)$ & $0(0,1)$ & $0(0,1)$ & $0(0,1)$ & 0.19 \\
\hline Steatosis $(>5$ present $)(m=1)$ & $209(63.5)$ & $97(61.0)$ & $112(65.9)$ & 0.36 \\
\hline Total HAI inflammation $(m=1)$ & $8(6,10)$ & $8(7,10)$ & $9(6,11)$ & 0.58 \\
\hline \multicolumn{4}{|l|}{ Iron score $(m=35)$} & 0.09 \\
\hline 0 & $157(53.2)$ & $66(47.5)$ & $91(58.3)$ & \\
\hline 1 & $115(39.0)$ & $62(44.6)$ & $53(34.0)$ & \\
\hline 2 & $23(7.8)$ & $11(7.9)$ & $12(7.7)$ & \\
\hline \multicolumn{5}{|l|}{ Serum lipid measures } \\
\hline TG (mg/dL) & $102.5(75,146)$ & $105.5(74.5,151)$ & $98.5(76,137)$ & 0.21 \\
\hline $\mathrm{LDLc}(\mathrm{mg} / \mathrm{dL})$ & $115.1(88.1,137.3)$ & $106.4(83.4,133.4)$ & $118.7(95.8,141.5)$ & 0.009 \\
\hline
\end{tabular}


Table 1 (Continued)

\begin{tabular}{llll}
\hline Feature $^{*}$ & Overall $(n=330)$ & AA $(n=160)$ & CA $(n=170)$ \\
\hline HDLc $(\mathrm{mg} / \mathrm{dL})$ & $41.8(33.7,53.8)$ & $42.3(32.9,54.6)$ & $41.3(33.8,52.0)$ \\
TC $(\mathrm{mg} / \mathrm{dL})$ & $185(157,207)$ & $179(153.5,204.5)$ & $187(161,209)$ \\
Dyslipidaemia & $232(70.3)$ & $110(68.8)$ & $122(71.8)$ \\
\hline
\end{tabular}

m, number with missing data; AA, African American; ALT, alanine aminotransferase; AST, aspartate aminotransferase; BMI, body mass index; CA, Caucasian American; HAI, histological activity index; HCV, hepatitis C virus; HDLc, high-density lipoprotein cholesterol; INR, international normalized ratio; LDLc, low-density lipoprotein cholesterol; TC, total cholesterol; TG, triglyceride, TIBC, total iron-binding capacity; WBC, white blood cell count.

*Each categorical variable is summarized as $n(\%)$ with $P$-values corresponding to a Pearson's chi-square test (nominal variables) or the Jonckheere-Terpstra test (ordinal variables) or exact equivalents, where appropriate; each continuous variable is summarized as a median (interquartile range) with a $P$-value corresponding to a Wilcoxon rank sum test.

$\dagger$ For features with two or more categories, the global $P$-value is listed in the first row of the feature. Where the global $P$-value is $<0.05, P$-values correspond to Pearson's chi-square with comparisons as follows:

tEach health insurance status category compared to other categories combined.

§Less than high school vs high school degree or more; high school degree vs more than high school degree; some college vs more than some college.

『Each genotype compared to other categories combined.

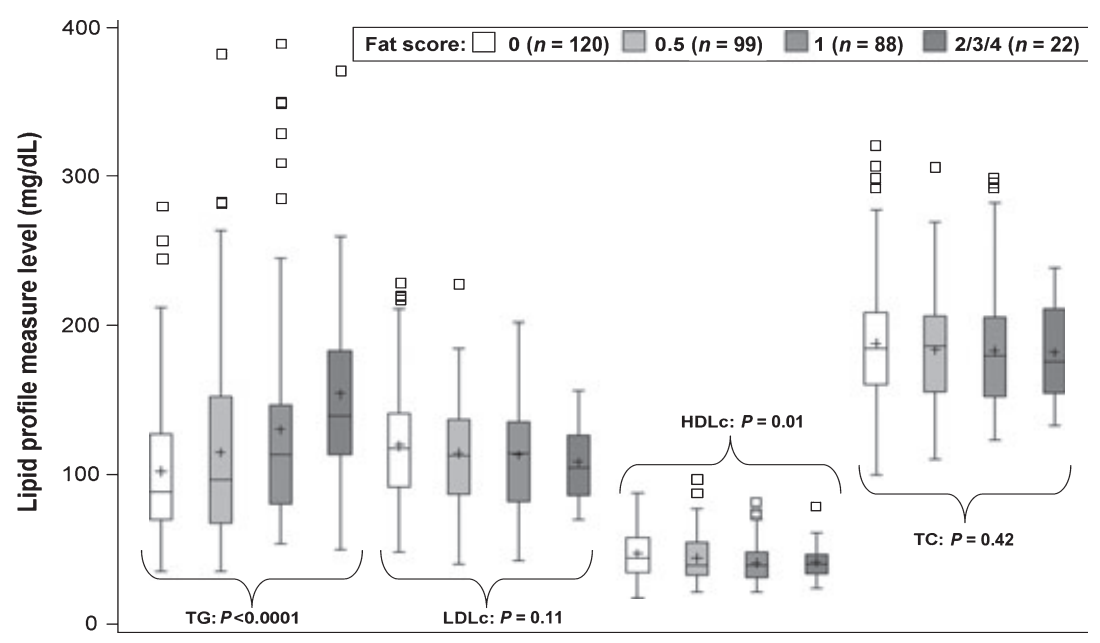

Fig. 1 Lipid measures by liver fat score. P-values correspond to a test of trend with fat score. [Trend test for triglyceride (TG), high-density lipoprotein cholesterol, and total cholesterol on the natural log scale]. NOTE: Boxplots exclude three extreme TG level outliers: $980 \mathrm{mg} / \mathrm{dL}$ (fat score $=0.5$ ); 481 and $600 \mathrm{mg} / \mathrm{dL}$ (fat score $=1$ ). [Correction made on 16 November 2010 , after online publication: amendment in the legend for figure 1].

Kruskal-Wallis tests. For all statistical tests, a P-value of $<0.05$ was considered statistically significant.

Linear regression was employed to model each lipid measure as a continuous outcome. Associations of lipid profile measures with hepatic fat score were assessed using linear regression with lipid profile measures as dependent variables. In regression models, TG, HDLc and TC were transformed to the natural logarithm (ln) scale to achieve normality. Independent variables were transformed to make associations with lipid profile measures linear and were centred about their means. In multivariable analyses, a stepwise selection approach was used for variable reduction. Associations between predictors of interest and each serum lipid measure were first evaluated for adjusting for race and age. Accounting for race and age, variables not retained in any final multivariable model included smoking status, alcohol consumption, body mass index (BMI), diabetes status and hypertension status, ALT, AST, total bilirubin, INR, Ishak fibrosis as a continuous measure and steatosis as a dichotomous measure ( $>5 \%$ fat involvement). All analyses 
were conducted using Statistical Analysis Software (SAS) version 9 (Carey, NC, USA) or STATA version 9 (College Station, TX, USA).

\section{RESULTS}

Characteristics of the study cohort are summarized by race (Table 1). AAs did not significantly differ from CAs by age, gender, employment status, health risk behaviours (smoking status and weekly alcohol consumption), viral level, AST, INR, WBC count, platelet count, per cent iron/TIBC, Ishak fibrosis, total HAI score, steatosis, TG, HDLc or TC. Compared to CAs, a larger percentage of AAs had health insurance coverage $(87 \%$ vs $78 \%, P=0.04)$, public health insurance $(31 \%$ vs $18 \%, \quad P=0.006)$, less education $(P=0.008)$, a history of diabetes $(15 \%$ vs $4 \%, P<0.001)$ or hypertension $(40 \%$ vs $19 \%, P<0.001)$ and higher prevalence of $\mathrm{HCV}$ subtype $1 \mathrm{~b}(44 \%$ vs $28 \%, P=0.002)$. As a group, AAs had higher BMI (median 29.3 vs $27.4 \mathrm{~kg} / \mathrm{m}^{2}$, $P<0.001$ ), higher alkaline phosphatase (median 83 vs $78 \mathrm{U} / \mathrm{L}, \quad P=0.043$ ) and ferritin levels (median 246 vs $149 \mathrm{ng} / \mathrm{mL}, P<0.001$ ), and lower ALT (median 60 vs $74.5 \mathrm{U} / \mathrm{L}, P<0.001$ ), total bilirubin (median 0.06 vs $0.07 \mathrm{mg} / \mathrm{dL}, P=0.004$ ), albumin (median $4.2 \mathrm{vs} 4.2 \mathrm{~g} / \mathrm{dL}$, $P=0.004$ ) and LDLc levels (median $106.4 \mathrm{vs} 118.7 \mathrm{mg} / \mathrm{dL}$, $P=0.009$ ) than CAs. The prevalence of dyslipidaemia was $70 \%$ overall and did not significantly differ by race.

Liver disease severity was associated with lipid profile measures. (Figs 1 and 2) Patients with severe fibrosis tended to have lower HDLc and TC levels compared to those without severe fibrosis (median 39.4 vs $45.5 \mathrm{mg} / \mathrm{dL}, P=0.002$; median 172 vs $188 \mathrm{mg} / \mathrm{dL}, \quad P=0.004$, respectively). (Fig. 1) In contrast, compared to patients with lower fat scores, patients with higher fat scores tended to have higher TG (medians 89, 97, 114.5 and $139.5 \mathrm{mg} / \mathrm{dL}, P<0.0001$ for trend: 0, 0.5, 1 and 2 or greater fat score, respectively) and lower HDLc levels (medians 45, 40.1, 39.4 and $40.9 \mathrm{mg} / \mathrm{dL}, P=0.01$ for trend: $0,0.5,1$ and 2 or greater fat score, respectively). (Fig. 2).

Iron study measures were significantly associated with lipid profile measures in multivariable models (ferritin: In TG $\beta=0.02, P=0.003$; and per cent iron/TIBC: In HDLc $\beta=-0.01, P=0.001$ ). (Table 2) Furthermore, the association between serum ferritin and LDLc levels significantly differed by race $(P<0.0001)$, such that for a decline in LDLc of $100 \mathrm{ng} / \mathrm{mL}$, the increase in ferritin was significantly larger in CAs compared to AAs (CA: $\beta=-3.4, P<0.0001$; AA: $\beta=-1.7, P=0.0001$ ). (Table 2 ).

Significant direct relationships were found between the natural logarithm (ln) of TG and $\log _{10}$ viral level in unadjusted $(\beta=0.11, P=0.003)$ and multivariable regression models $(\beta=0.09, P=0.01$ ). (Fig. 3 and Table 2) Other factors associated with lipid profile measures in multivariable models (Table 2) were aspects of histological liver disease, including HAI inflammation that was inversely related to LDLc and the $\ln$ of TC, severe Ishak fibrosis associated with lower $\ln$ HDLc levels $(\beta=-0.10, P=0.006)$ and fat score directly related to the $\ln$ of TG $(\beta=0.17, P<0.001)$.

\section{DISCUSSION}

In this cohort of people with treatment-naïve chronic HCV genotype 1 infection, there was significant direct association between HCV viral load and TG levels, the latter of which is mainly present in VLDL. This is relevant to proposed biological mechanisms of HCV replication and secretion from hepatocytes. Potentially important in the context of HCVinduced liver damage, steatosis was also associated with higher TG levels. In contrast to TG levels, other lipid profile measures were lower among those with advanced liver disease as measured by hepatic fibrosis, fat involvement and inflammation.

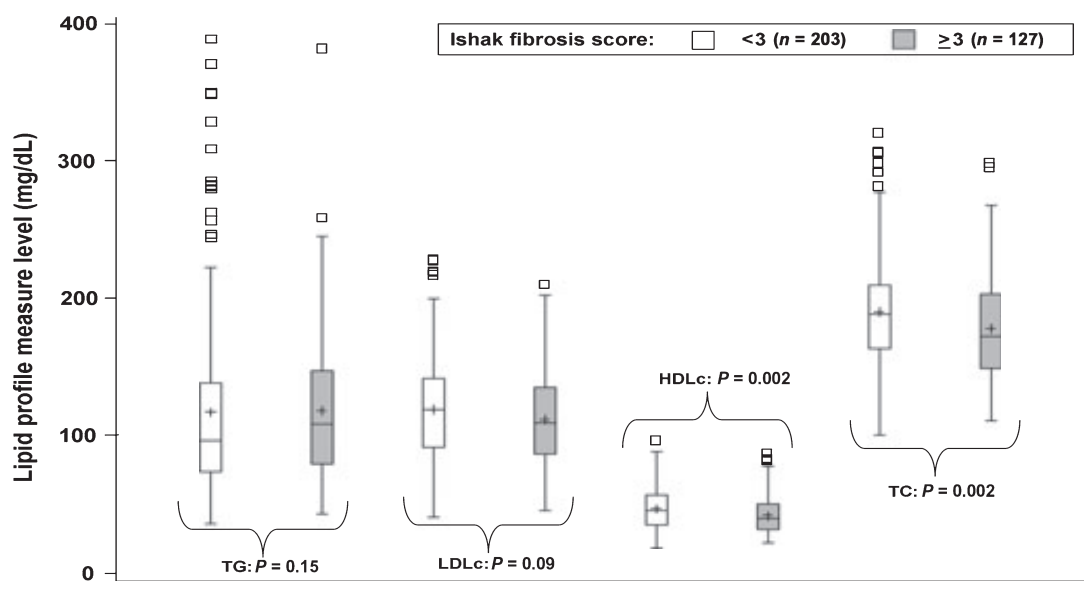

Fig. 2 Lipid profile measures by Ishak fibrosis score. P-values correspond to Wilcoxon rank sum tests of differences by fibrosis score (Ishak fibrosis score $\geq 3$ vs Ishak fibrosis score <3). NOTE: Boxplots exclude three extreme TG level outliers: 600 and 980 $\mathrm{mg} / \mathrm{dL}$ (nonsevere fibrosis); $481 \mathrm{mg} / \mathrm{dL}$ (severe fibrosis). [Correction made on 16 November 2010 after online publication: amendment in the legend for figure 2]. 


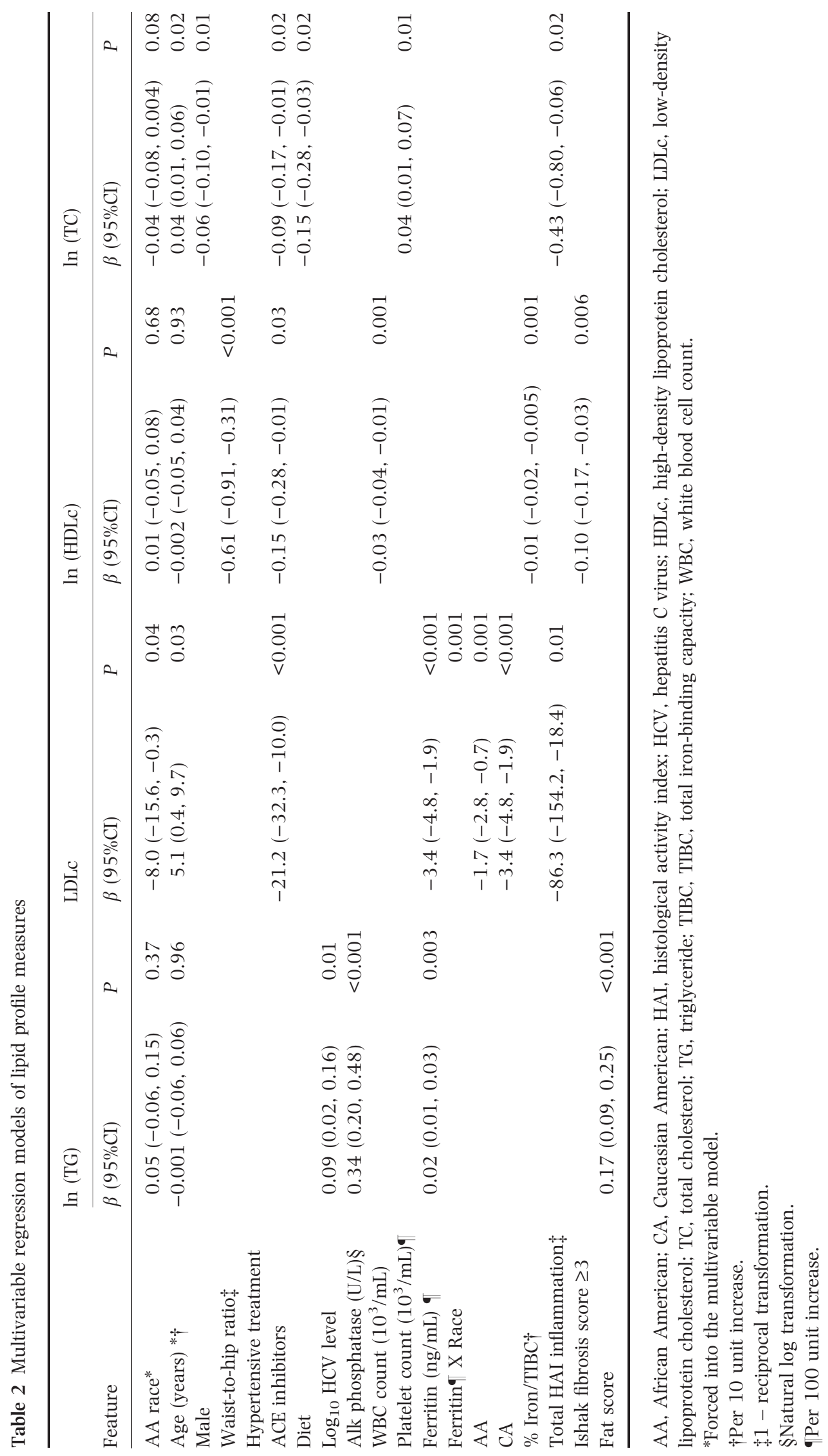




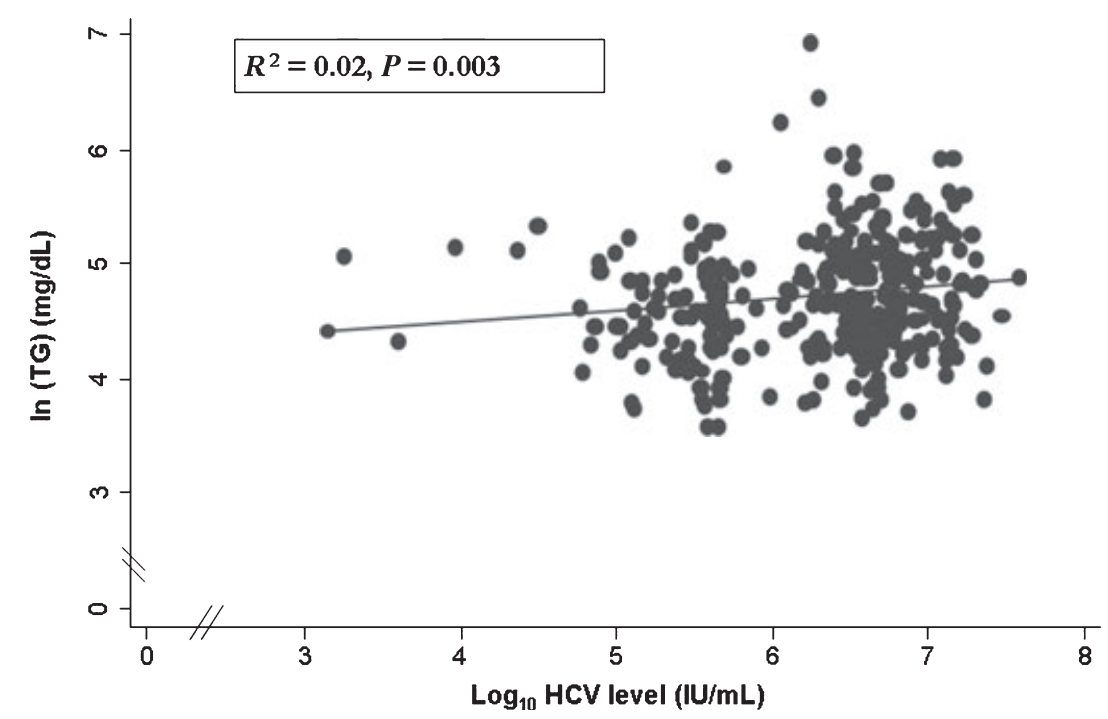

Fig. 3 Relationship between triglyceride (TG) and hepatitis C virus (HCV) RNA levels. In = natural log transformation. Backtransformed, one $\log _{10}$ increase in HCV level corresponds to an $11.4 \mathrm{mg} / \mathrm{dL}$ TG increase on the raw scale.

The significant direct relationship between HCV titres and TG levels is consistent with findings from in vitro work suggesting that HCV is secreted from hepatocytes into the serum complexed with VLDL [23-27]. In transgenic mouse models, inhibition of the microsomal TG transfer protein by exposure to HCV core protein has been proposed as a mechanism of HCV-induced steatosis, a plausible basis for associations between low beta-lipoprotein levels and chronic HCV infection [26]. This mechanism is supported by two epidemiological studies, which found inverse relationships between steatosis and TC, TG, and apolipoprotein B levels in a genotype 3-infected group, but not in genotype 1 [12,13]. In contrast, there was a direct relationship between TG and liver fat score in the present study and in the larger VirahepC cohort [10]. The inconsistent relationships between steatosis and TG among studies may be attributed to the Virahep-C study being an exclusively genotype 1-infected group and differences in the aetiology of steatosis by HCV genotype [33,34]. Whereas steatosis is posited to occur because of metabolic changes in genotype 1 infection, studies suggest that steatosis associated with genotype 3 occurs by a direct viral-induced process.

The current study found associations between steatosis and severe fibrosis with lower HDLc and severe fibrosis with lower TC levels. These findings are consistent with other findings from both non-HCV-infected $[11,14]$ and chronically HCV-infected groups $[12,13]$ that have associated liver disease with lower levels of HDLc and TC. The inverse relationship between liver disease and non-TG lipid profile measures may reflect the disruption of lipid and lipoprotein metabolism because of liver damage, albeit by host factors (e.g. poor nutrient intake, alcohol consumption or excess body weight) or attributed to chronic HCV infection [35].
As potential indicators of liver damage, serum iron measures (ferritin and the per cent iron/TIBC) were related to the lipid profile (TG directly, other lipid profile measures indirectly). In addition, the iron measures were significantly higher for those with severe fibrosis, steatosis or hepatic iron deposition (data not shown). These findings are consistent with a report from a non-HCV-exposed cohort, which found significantly lower HDLc and higher TG levels in a group with high ferritin levels of at least $100 \mathrm{ng} / \mathrm{mL}$ ferritin levels, compared to those below this cutpoint [36]. Findings are also consistent with another study of exclusively HCVinfected people, which found a direct relationship between ferritin and liver fat [37]. Other work using National Health and Nutrition Examination Survey (NHANES) data has reported associations between elevated ferritin and iron saturation in HCV-infected, compared to a nonexposed group of people [38-40]. These studies suggest a relationship between serum iron measures, liver disease and the lipid profile, which may be impacted by chronic HCV infection; however, biological mechanisms are unclear.

This study is not without limitation. Given the cross-sectional nature of this analysis, it is not possible to infer causation or temporality of relationships between lipid profile and liver disease measures. Despite this limitation, this study has a number of strengths in that it assessed factors associated with lipid profile measures, which may have implications to proposed mechanisms of HCV entry into hepatocytes, replication and secretion from hepatocytes into the serum. In addition, the Virahep-C cohort, which by design enrolled and treated approximately equal numbers of AAs and CAs, afforded a unique opportunity to assess whether factors associated with the lipid profile differed by race. 
In conclusion, the current study found associations between lipid profile measures and both HCV level and liver disease measures. These findings may guide further investigations into the impact of antiviral therapy on the lipid profile, as well as the evaluation of lipid profile measures as predictors of treatment efficacy.

\section{ACKNOWLEDGEMENTS}

Additional funding for lipid profile analyses and support for Dr L.J. Yee was provided in part by grant KL2 RR024154-02 (to LJY).

\section{DISCLOSURE STATEMENT}

The authors of this manuscript have no financial disclosures to report.

\section{REFERENCES}

1 Armstrong GL, Wasley A, Simard EP, McQuillan GM, Kuhnert WL, Alter MJ. The prevalence of hepatitis C virus infection in the United States, 1999 through 2002. Ann Intern Med 2006; 144(10): 705-714.

2 Armstrong GL, Alter MJ, McQuillan GM, Margolis HS. The past incidence of hepatitis $\mathrm{C}$ virus infection: implications for the future burden of chronic liver disease in the United States. Hepatology 2000; 31(3): 777-782.

3 Leigh JP, Bowlus CL, Leistikow BN, Schenker M. Costs of hepatitis C. Arch Intern Med 2001; 161(18): 22312237.

4 Seaberg EC, Belle SH, Beringer KC, Schivins JL, Detre KM. Liver transplantation in the United States from 1987-1998: updated results from the Pitt-UNOS Liver Transplant Registry. Clin Transpl 1998; 17-37.

5 Jarmay K, Karacsony G, Nagy A, Schaff Z. Changes in lipid metabolism in chronic hepatitis C. World J Gastroenterol 2005; 11(41): 6422-6428.

6 Marzouk D, Sass J, Bakr I et al. Metabolic and cardiovascular risk profiles and hepatitis $\mathrm{C}$ virus infection in rural Egypt. Gut 2007; 56(8): 1105-1110.

7 Moritani M, Adachi K, Arima N et al. A study of arteriosclerosis in healthy subjects with HBV and HCV infection. J Gastroenterol 2005; 40(11): 1049-1053.

8 Siagris D, Christofidou M, Theocharis GJ et al. Serum lipid pattern in chronic hepatitis C: histological and virological correlations. J Viral Hepat 2006; 13(1): 56-61.

9 Targher G, Bertolini L, Padovani R, Rodella S, Arcaro G, Day C. Differences and similarities in early atherosclerosis between patients with non-alcoholic steatohepatitis and chronic hepatitis B and C. J Hepatol 2007; 46(6): 11261132.

10 Conjeevaram HS, Kleiner DE, Everhart JE et al. Race, insulin resistance and hepatic steatosis in chronic hepatitis C. Hepatology 2007; 45(1): 80-87.

11 Kotronen A, Westerbacka J, Bergholm R, Pietilainen KH, Yki-Jarvinen H. Liver fat in the metabolic syndrome. J Clin Endocrinol Metab 2007; 92(9): 3490-3497.
12 Petit JM, Benichou M, Duvillard L et al. Hepatitis C virusassociated hypobetalipoproteinemia is correlated with plasma viral load, steatosis, and liver fibrosis. Am J Gastroenterol 2003; 98(5): 1150-1154.

13 Serfaty L, Andreani T, Giral P, Carbonell N, Chazouilleres O, Poupon R. Hepatitis C virus induced hypobetalipoproteinemia: a possible mechanism for steatosis in chronic hepatitis C. J Hepatol 2001; 34(3): 428-434.

14 Cicognani C, Malavolti M, Morselli-Labate AM, Zamboni L, Sama C, Barbara L. Serum lipid and lipoprotein patterns in patients with liver cirrhosis and chronic active hepatitis. Arch Intern Med 1997; 157(7): 792-796.

15 Carriere M, Rosenberg AR, Conti F et al. Low density lipoprotein receptor transcripts correlates with liver hepatitis C virus RNA in patients with alcohol consumption. J Viral Hepat 2006; 13(9): 633-642.

16 Molina S, Castet V, Fournier-Wirth C et al. The low-density lipoprotein receptor plays a role in the infection of primary human hepatocytes by hepatitis C virus. J Hepatol 2007; 46(3): 411-419.

17 Monazahian M, Bohme I, Bonk S et al. Low density lipoprotein receptor as a candidate receptor for hepatitis $\mathrm{C}$ virus. J Med Virol 1999; 57(3): 223-229.

18 Petit JM, Minello A, Duvillard L et al. Cell surface expression of LDL receptor in chronic hepatitis C: correlation with viral load. Am J Physiol Endocrinol Metab 2007; 293(1): E416E420.

19 Hennig BJ, Hellier S, Frodsham AJ et al. Association of low-density lipoprotein receptor polymorphisms and outcome of hepatitis C infection. Genes Immun 2002; 3(6): 359-367.

20 von Hahn T, Lindenbach BD, Boullier A et al. Oxidized low-density lipoprotein inhibits hepatitis C virus cell entry in human hepatoma cells. Hepatology 2006; 43(5): 932942.

21 Kapadia SB, Barth H, Baumert T, McKeating JA, Chisari FV. Initiation of hepatitis $\mathrm{C}$ virus infection is dependent on cholesterol and cooperativity between CD81 and scavenger receptor B type I. J Virol 2007; 81(1): 374-383.

22 Molina S, Castet V, Pichard-Garcia L et al. Serum-derived hepatitis $\mathrm{C}$ virus infection of primary human hepatocytes is tetraspanin CD81 dependent. J Virol 2008; 82(1): 569574.

23 Gastaminza P, Cheng G, Wieland S, Zhong J, Liao W, Chisari FV. Cellular determinants of hepatitis C virus assembly, maturation, degradation and secretion. J Virol 2007; 82(5): 2120-2129.

24 Huang H, Sun F, Owen DM et al. Hepatitis C virus production by human hepatocytes dependent on assembly and secretion of very low-density lipoproteins. Proc Natl Acad Sci U S A 2007; 104(14): 5848-5853.

25 Nielsen SU, Bassendine MF, Burt AD, Martin C, Pumeechockchai W, Toms GL. Association between hepatitis C virus and very-low-density lipoprotein (VLDL)/LDL analyzed in iodixanol density gradients. J Virol 2006; 80(5): 2418-2428.

26 Perlemuter G, Sabile A, Letteron P et al. Hepatitis C virus core protein inhibits microsomal triglyceride transfer protein activity and very low density lipoprotein secretion: a 
model of viral-related steatosis. FASEB J 2002; 16(2): 185194.

27 Ye J. Reliance of host cholesterol metabolic pathways for the life cycle of hepatitis C virus. PLoS Pathog 2007; 3(8): e108.

28 Conjeevaram HS, Fried MW, Jeffers LJ et al. Peginterferon and ribavirin treatment in African American and Caucasian American patients with hepatitis C genotype 1. Gastroenterology 2006; 131(2): 470-477.

29 Friedewald WT, Levy RI, Fredrickson DS. Estimation of the concentration of low-density lipoprotein cholesterol in plasma, without use of the preparative ultracentrifuge. Clin Chem 1972; 18(6): 499-502.

30 Executive Summary of The Third Report of The National Cholesterol Education Program (NCEP) Expert Panel on Detection, Evaluation, And Treatment of High Blood Cholesterol In Adults (Adult Treatment Panel III). JAMA. 2001; 285 (19): 2486-2497.

31 Ishak K, Baptista A, Bianchi L et al. Histological grading and staging of chronic hepatitis. J Hepatol 1995; 22(6): 696699.

32 Knodell RG, Ishak KG, Black WC et al. Formulation and application of a numerical scoring system for assessing histological activity in asymptomatic chronic active hepatitis. Hepatology 1981; 1(5): 431-435.

33 Adinolfi LE, Gambardella M, Andreana A, Tripodi MF, Utili R, Ruggiero G. Steatosis accelerates the progression of liver damage of chronic hepatitis $\mathrm{C}$ patients and correlates with specific HCV genotype and visceral obesity. Hepatology 2001; 33(6): 1358-1364.

34 Asselah T, Rubbia-Brandt L, Marcellin P, Negro F. Steatosis in chronic hepatitis C: why does it really matter? Gut 2006; 55(1): 123-130.

35 Sherlock S, James D. Diseases of the Liver and Biliary System, 10th edn. London, UK: Blackwell Science Ltd, 1997.

36 Zelber-Sagi S, Nitzan-Kaluski D, Halpern Z, Oren R. NAFLD and hyperinsulinemia are major determinants of serum ferritin levels. J Hepatol 2007; 46(4): 700-707.

37 Valenti L, Pulixi EA, Arosio P et al. Relative contribution of iron genes, dysmetabolism and hepatitis $\mathrm{C}$ virus (HCV) in the pathogenesis of altered iron regulation in HCV chronic hepatitis. Haematologica 2007; 92(8): 1037-1042.

38 Ioannou GN, Dominitz JA, Weiss NS, Heagerty PJ, Kowdley $\mathrm{KV}$. Racial differences in the relationship between hepatitis C infection and iron stores. Hepatology 2003; 37(4): 795801.

39 Shaheen M, Echeverry D, Oblad MG, Montoya MI, Teklehaimanot S, Akhtar AJ. Hepatitis C, metabolic syndrome, and inflammatory markers: results from the Third National Health and Nutrition Examination Survey [NHANES III]. Diabetes Res Clin Pract 2007; 75(3): 320326.

40 Shan Y, Lambrecht RW, Bonkovsky HL. Association of hepatitis $\mathrm{C}$ virus infection with serum iron status: analysis of data from the third National Health and Nutrition Examination Survey. Clin Infect Dis 2005; 40(6): 834-841. 